ERRATUM

Fred E. Avni · Laurent Garel · Marie Cassart •

Anne Massez • Daniele Eurin · François Didier •

Michelle Hall • Rita L. Teele

\title{
Perinatal assessment of hereditary cystic renal diseases: the contribution of sonography
}

Published online: 28 April 2006

C) Springer-Verlag 2006

The online version of the original article can be found at http://dx. doi.10.1007/s00247-005-0075-0

F. E. Avni $(\square) \cdot$ M. Cassart · A. Massez

Department of Medical Imaging, Erasme Hospital,

Route de Lennik 808,

1070 Brussels, Belgium

e-mail: Favni@ulb.ac.be

Tel.: +32-2-5556892

Fax: $+32-2-5554545$

L. Garel

Department of Paediatric Imaging,

Sainte Justine Hospital,

Montréal, Québec, Canada

D. Eurin

Department of Paediatric Imaging,

Charles Nicolle Hospital,

Rouen, France

F. Didier

Department of Paediatric Imaging,

A. Pinard Regional Maternity Hospital,

Nancy, France

M. Hall

Department of Pediatric Nephrology,

Erasme Hospital,

Brussels, Belgium

R. L. Teele

Department of Radiology,

Starship Children's Hospital,

Auckland, New Zealand

\section{Pediatr Radiol (2006) 36:405-414}

The title of Table 8 should be "The differential diagnosis of bilateral hyperechoic kidneys" and not "Bilateral multiple cysts". 